THE KURUME MEDICAL JOURNAL Vol. 17, No. 3, 1970

\title{
IRREGULAR DISTRIBUTION OF THE ANTIGENIC EPITHELIAL GLYCOPROTEIN IN GASTRIC CANCER
}

\author{
HIROSHI KAWASAKI AND KATSUJIRO IMASATO
}

First Department of Pathology, Kurume University School of Medicine, Kurume, Japan

\author{
EIJI KIMOTO, HIKOJIRO FUNATSU AND YOSHIAKI NOGUCHI \\ Institute of Clinical Pathology, Kurume University School of Medicine, \\ Kurume, Japan \\ KAZUKO AKIYAMA \\ Department of Legal Medicine, Kurume University School of Medicine, \\ Kurume, Japan
}

(Received for publication May 8, 1970)

The carbohydrate-protein complexes occurring in the mucous epithelium of gastrointestinal tract have been extensively studied in recent years ${ }^{1 /-3)}$. One of the predominant components isolated from these sources was found to belong to the neutral mucopolysaccharide or fucomucan in the carbohydrate type and, therefore, to be closely similar in chemical and physicochemical properties to the water-soluble blood-group substances ${ }^{4) 5}$. Structural investigations on these glycoproteins have been directed primarily towards their carbohydrate moiety and especially the terminal carbohydrate residues which are the determinants for the blood-group activity.

Apart from the blood-group activity of these kinds of glycoproteins, our previous studies ${ }^{6)}$ ) revealed that the epithelial glycoprotein isolated from human gastric mucosa gave the specific precipitate line with rabbit immune serum in the Ouchterlony double diffusion test and that, though this material possessed a high ABO blood-group activity in the hemagglutination-inhibition test, the precipitate reaction was independent of the blood-groups of materials. Using the fluorescent antibody technic, this antigenic glycoprotein was demonstrated to be localized intensely in mucoid cells and mucus secretion within the normal mucosa but not in other layers of stomach.

Attempts in this experiment were devoted into the demonstration of the glycoprotein in gastric cancer tissues with an immunofluorescent technic and, especially, into the investigation how it would be distributed in cancer cells of different types. 


\section{MATERIALS AND METHODS}

\section{1) Isolation and immunochemical characterization of epithelial glyco- protein from human gastric mucosa}

Human gastric mucosas were obtained at autopsy from corpus organs which were diagnosed to be suffered from none of any gastric diseases. They were stored in several changes of acetone and then dried to obtain the tissue powder.

Extraction of the glycoprotein was carried out with the principally same procedures as those employed in the previous works ${ }^{6)}{ }^{7}$ ). The crude material was extracted with ethylene glycol as devised by Tiba et al. ${ }^{8}$, sedimented from its clear supernatant with an addition of alcohol containing acetic acid and sodium acetate and then subjected to the digestion with amylase and the Sevag procedure to remove protein impurities.

The purification procedures were replaced by the gel filtration through Sepharose $4 \mathrm{~B}$ column as recommended by Hiyama ${ }^{9}$ and then the preparative electrophoresis in Pevikon C-870 powder block ${ }^{10}$ ). Chemical constituents of the isolated material were determined as described before ${ }^{11}$.

The purified material was employed for immunization into rabbits to obtain antisera. Rabbits, weighing approximately $3 \mathrm{~kg}$, were immunized by four footpad injections of the material ( $20 \mathrm{mg}$ in each injection) emulsified by adding the complete Freund's adjuvant over a period of 7 weeks. The antiserum was absorbed completely with lyophilized human serum and liver powder. Against this antiserum, the antigenic activities and properties of various tissue extracts or body fluids were examined by the Ouchterlony double diffusion test and immunoelectrophoresis as employed in routine works.

\section{2) Immunohistological studies (Direct FITC-labeled antibody technic)}

The gamma globulin fraction of antiserum was conjugated to fluorescein isothiocyanate (FITC). The FITC-labeled gamma globulin was isolated by passing through a column of Sephadex G-25 and through a DEAE cellulose column, according to a routinely employed method ${ }^{12}$. The labeled antiserum was absorbed with human serum and liver as described before, in order to remove the components responsible for nonspecific fluorescence.

Twenty-one cases of gastric cancers consisted of 6 carcinoma simplex and 15 adenocarcinoma, were obtained at gastrectomy. They were histologically classified according to "The general role for the gastric cancer study in surgery and pathology" ${ }^{13)}$, as shown in Table 1 . The cancer tissues were fixed in cold alcohol and embedded in paraffin Erstarr. -P. etwa $52-54^{\circ} \mathrm{C}$. The tissue sections were submitted for fluorescent staining and also for hematoxyline-eosin, PAS and alcian blue stain. The immunofluorescence preparations were examined under a fluorescence microscope (Nikon, SAR-F). Photos were taken with Fujicolor R 100 film. 
TABLE 1

Classification of the examined gastric cancers

\begin{tabular}{|c|c|c|c|c|c|c|c|}
\hline $\begin{array}{l}\text { Case } \\
\text { No. }\end{array}$ & $\underset{\text { type }}{\text { Fundamental }}$ & CAT & SAT & INF & Histological & Functional & Stromal \\
\hline 1 & Ca. simplex & II & 3 & $\beta$ & microalveolare & & medullare \\
\hline 2 & " & III & 3 & $\gamma$ & " & mucocellulare & " \\
\hline 3 & " & II & 3 & $\gamma$ & $"$ & & " \\
\hline 4 & " & II & 3 & $\gamma$ & macroalveolare & & " \\
\hline 5 & " & 且 & 3 & $\gamma$ & microalveolare & & " \\
\hline 6 & " & III & 3 & $\gamma$ & " & & \\
\hline 7 & Adenoca. & II & 3 & $\beta$ & acinosum & & medullare \\
\hline 8 & " & III & 3 & $\gamma$ & " & & " \\
\hline 9 & " & II & 2 & $\gamma$ & tubulare & & \\
\hline 10 & " & III & 3 & $\gamma$ & " & mucocellulonodulare & \\
\hline 11 & " & II & 2 & $\beta$ & " & muconodulare & \\
\hline 12 & " & III & 3 & $\beta$ & " & & medullare \\
\hline 13 & " & II & 2 & $\beta$ & " & & \\
\hline 14 & " & III & 3 & $\gamma$ & " & mucocellulonodulare & medullare \\
\hline 15 & " & II & 2 & $\gamma$ & " & & \\
\hline 16 & " & III & 3 & $\gamma$ & " & muconodulare & \\
\hline 17 & " & II & 3 & $\gamma$ & " & & \\
\hline 18 & " & III & 2 & $\beta$ & " & muconodulare & \\
\hline 19 & $"$ & II & 2 & $\gamma$ & papillare & " & \\
\hline 20 & " & $\mathbb{I}$ & 2 & $\gamma$ & " & & \\
\hline 21 & " & $\mathbb{I}$ & 2 & $\gamma$ & " & muconodulare & medullare \\
\hline
\end{tabular}

\section{RESULTS}

The epithelial glycoprotein from human gastric mucosa, eluted in a void volume through Sepharose $4 \mathrm{~B}$ column and migrated towards the cathode on electrophoresis, possessed the fucomucan-type carbohydrate constituents including fucose, galactose, glucosamine and galactosamine and 20 per cent or less protein moiety in which threonine and serine were predominant. It might be, therefore, characterized as the blood-group specific glycoprotein, as reported previously.

Against the antiserum, it gave a precipitate line specific grossly for gastric mucosa and juice on the Ouchterlony test and developed a precipitate arc in gamma globulin region on immunoelectrophoresis. This precipitate reaction was not inhibited by appropriate red-cell absorptions of the antiserum, but it occurred independently on different blood-group materials.

On the immunofluorescence preparations from the normal stomach (Photo 1), this antigenic glycoprotein was found throughout the mucosa, especially in 
mucoid cells and secreted mucus, and the intensity of specific fluorescence correlated well with the intensity of PAS staining. The fluoresced cells were much more abundant in the pyloric portion than in the fundic and cardiac portion of stomach. They were never demonstrated in other layers of the stomach.

In the cases of gastric cancers, the fluorescence materials were irregularly distributed. Some typical immunohistological features of cancer tissues are shown in Photo 2-12.

The well-differentiated adenocarcinoma of tubular or papillary structure contained little mucus in cells which concordantly were less fluoresced.

On the other hand, the undifferentiated cancer cells of carcinoma simplex, proliferated diffusely within the mucosa, contained much mucus in their cytoplasms and also the intense fluorescent materials. And similarly the cancer cells from either carcinoma simplex or adenocarcinoma, which infiltrated diffusely into the submucosal or muscular layers, were well fluoresced.

In the area where the intestinal metaplasia was remarkable and the alcian blue-stainable cells became abundant, the fluorescence decreased.

Where the mucinous degeneration was prominant, the fluorescence was seen in the PAS-positive cytoplasms or mucus contiguous to the cell surfaces but not in the alcian blue positive ones. This might be reasonably recognized from the fact that the antibody directed towards the PAS-positive "fucomucan type" glycoprotein but not towards the PAS-alcian blue stainable "sialomucan type" one which occurred in abundant in mucinous carcinoma as reported previously by one of the authors ${ }^{14}$.

\section{DISCUSSION}

The immunochemistry and immunohistology in the study of cancer has primarily concerned with the question of whether cancerous tissues contain the cancer-specific antigen and, if so, what they are and how they are distributed (5)-18). There are also some evidences that loss of isoantigen or any organ-specific substances is associated with malignant change. For the total immunochemical grasp of the cancer problem, therefore, there might be various profiles of the malignant state including antigenic gain, deletion, diversion and reversion.

Glynn et al. ${ }^{19)}$ carried out the immunofluorescence experiments using anti-A, anti-Le ${ }^{a}$ and anti-H rabbit antisera prepared with ovarian cyst antigens. They demonstrated a persistency of such blood-group substances, which are not organ-specific, in gastric carcinoma. Nairn et al. ${ }^{20}{ }^{21}$ ) reported on an isolation of gastro-intestinal-specific antigen from a microsomal fraction of normal human colon mucosa, characterized as an acid mucopolysaccharide, and on a depletion of such organ-specific antigen from colonic and gastric carcinomas. More recently, Häkkinen et al. ${ }^{22)}$ demonstrated an antigenicity in gastric 
cancer cells with secretory activity but absent in all benign epithelium, using rabbit antiserum against sulphoglycoproteins from human gastric juice.

In our immunohistological studies, the antiserum directed towards the antigenic determinants of epithelial glycoprotein showing gross organ-specificity for gastric mucosa. The results revealed that, though the well-differentiated cancer cells of non-secretory activity were devoid of such antigen, the diffusely and invasively proliferated cancer cells possessed or secreted the same (or the cross-reacted) antigenic glycoprotein correlating well with PAS staining. It might be noteworthy that such antigenic epithelial glycoprotein, which would be a product of adaptation and differentiation of the normal mucus secreting cells, is demonstrated rather in the undifferentiated malignant cells.

Because of the difference in the preparation of antigen and therefore antibody activities employed in these different works, it is difficult to compare our results with the formers. These points still remain to be solved. Especially, the antigenic determinants within such glycoprotein molecule beside those of blood-group activity are under investigation.

\section{SUMMARY}

The epithelial glycoprotein was isolated from normal human gastric mucosa. Though its chemical composition was the same as those of the water-soluble blood-group specific substances, the precipitate reaction against rabbit anti. serum was independent of the blood groups of materials and directed towards the organ-specificity for gastric mucosa.

On the immunofluorescence preparations from the normal stomach, this antigen distributed intensely in mucoid cells and secreted mucus within the mucosa. In gastric cancers, though the well-differentiated ones of non-secretory activity were devoid of such antigen, the diffusely and invasively proliferated ones possessed or secreted the same (or the cross-reacted) antigenic glycoprotein, correlating well with PAS staining.

\section{ACKNOWLEDGMENT}

The authors wish to thank Prof. T. Nakashima at First Department of Pathology, Prof. M. Takeuchi at Institute of Clinical Pathology and Prof. M. Hara at Department of Legal Medicine for their encouragement and advice.

\section{REFERENCES}

1) Werner, I. : Studies on glycoproteins from mucous epithelium and epithelial secretion. Acta Soc. Med. Upsalien., 58, 1, 1953.

2) OdIn, I. : Mucopolysaccharides of epithelial mucus. In Chemistry and Biology of Mucopolysaccharides. Ciba Foundation Symposium, Little, Brown aud Co., Boston, p. $234,1958$.

3) Brimocombe, J. S. and Webber, J. M. (Ed.) : Mucopolysaccharides. Chemical Structure, 
Distribution and Isolation. BBA Library Vol. 6, Elsevier Publ. Co., Amsterdam, 1964.

4) KaBAT, E. A. : Blood-Group substances. Their Chemistry and Immunochemistry. Academic Press, New York, 1956.

$5)$ Gottschalk, A.: Glycoproteins. Their Composition, Structure and Function. BBA Library Vol. 5, Elsevier Publ. Co., Amsterdam, 1966.

6) Akiyama, K., Noguchi, Y. and Kimoto, E. : Studies on organ-specific glycoprotein from human gastric mucosa. Publication on the 42th Jap. Biochem. Soc., 1969.

7) Noguchi, Y.: Immunochemical studies on the glycoprotein from human gastric mucosa. J. Kurume Med. Assoc., 32, 1358, 1969.

8 ) Tiba, H., Teramura, N. and Gotoh, A. : Hexosamine compounds in human gastric juice. Tohoku J. exp. Med., 50, 287, 1949.

9) Hiy ama, N. : Blood-group substances. Protein Nucleic Acid Enzyme, 14, 658, 1969.

10) MÜller-Eberhard, H. J. : A new supporting medium for preparative electrophoresis. Scand. J. Clin. Lab. Invest., 12, 33, 1960.

11) Kimcto, E., Kuranari, T., Mf suda, H. and Takeuchi, M. : Isolation and characterization of a glycopeptide from mucinous carcinoma of human stomach. J. Biochem., 63, 542, 1968.

12) Hamashima, Y. and Kyogoku, M. : Immunohistology. Igaku Shoin, Tokyo, 1968.

13) Jap. Res. Soc. for Grastric Cancer: The general role for the gastric cancer study in surgery and pathology. Kanehara Shuppan Co., Tokyo, 1968.

14) Kimoto, E., Tanaka, Y., Kuranari, T., Masuda, H. and Takeuchi, M. : Sialomucopolysaccharides of human cancerous stomach. Proc. Symp. Chem. Physiol. Pathol., 5, 122, 1965.

15) Zilber, L. A. : Specific tumor antigens. Advances in Cancer Res., 5, 291, 1958.

16) Gorer, P. A. : The antigenic structure of tumors. Advances in Immunol., Vol. 1, 345, 1962.

17) DAy, E. D. : The immunochemistry of cancer. Charles C Thomas Publ, Springfield, Ill., 1965.

18) Gold, P. and Freedman, S.: Specific carcinoembryonic antigens of the human digestive system. J. exp. Med., 122, 467, 1965.

i9) Glynn, L. E. and Holborow, M. A. : Distribution of blood-group substances in human tissues. Brit. med. Bull, 15, 150, 1959.

20) Nairn, R. C., Fothergill, J. E., McEntegart, M. G. and Porteous, I. B. : Gastrointestinal specific antigen : An immuno-histological and serological study. Brit. med. J., 2, 1788, 1962.

21) Nairn, R. C., Fothergill, J. E., McEntegart, M. E. and Richmond, H. G. : Loss of gastro-intestinal specific antigen in neoplasia. Brit. med. J., 2, 1791, 1962.

22) H.̈̈kKinen, I., Grönroos, J. and Kunnas, R. : Sulphoglycoproteins in normal, metaplastic and cancerous gastric mucosa as detected by immunofluorescence technique. Ann. Med. exp. Fenn., 45, 206, 1967. 


\section{EXPLANATION OF PLATES}

Photo 1. Normal gastric mucosa in the pyloric region.

The fluorescent materials are intensely located in mucoid cells at the bottom of glands of which cytoplasm are pale in HE stain and PAS-stainable. The mucus products in the gastric pits and the surface epithelium are also fluoresced.

Photo 2. Case No. 5 Carcinoma simplex.

The PAS-stainable cancer cells, proliferated diffusely within the mucosa, are intensely fluoresced.

Photo 3. Case No. 5 Higher magnification of photo 2.

Some cancer cells are stainable with PAS and others are with alcian blue. An intense fluorescence correlates fairly well with the intensity of PAS staining. The fluoresced cells vary diversely in the intensity and also in the feature.

Photo 4. Case No. 2 Carcinoma simplex.

The cancer cells, infiltrated into the musclar layer, are fluoresced as intensely as those in mucosa.

Photo 5. Case No.17 Adenocarcinoma, tubular type.

The cancer cells in the tubular structure, stainable in neither PAS nor alcian blue, are scarcely fluoresced. And in the surrounding area, where the intestinal metaplasia is remarkable and the alcian blue-stainable cells exist predominantly, the fluorescence is observed less intensely than the normal.

Photo 6. Case No.21 Adenocarcinoma, papillary type.

The cancer cells in the papillary structure are devoid mostly of fluorescence as shown in those in Photo 5. Some of the fluoresced mucus materials are scatterred in the limited area along the duct.

Photo 7. Case No. 20 Adenocarcinoma, papillary type.

Cancer cells, infiltrated diffusely into the submucosal and musclar layers, are fluoresced rather much intensely than those of the papillary structure in the mucosa.

Photo 8, 9. Case No. 19 and 21 Adenocarcinoma, papillary type.

Cancer cells, which proliferate in a papillary type in a cystic empties of submucosa, and also the secreted mucus of PAS-positive are intensely fluoresced.

Photo 10, 11 and 12. Case No.14 PAS-alcian blue and immunofluorescent staining of adenocarcinoma, tubular and mucocellulo-nodular type.

Cancerous tubules are composed mostly of the signet ring cells, among which some are positive in PAS stain and in both PAS and alcian blue and others in alcian blue only (Photo 10). Among these cells in both layers of mucosa (Photo 11) and submucasa (Photo 12), only the PAS-positive ones are intensely fluoresced, 

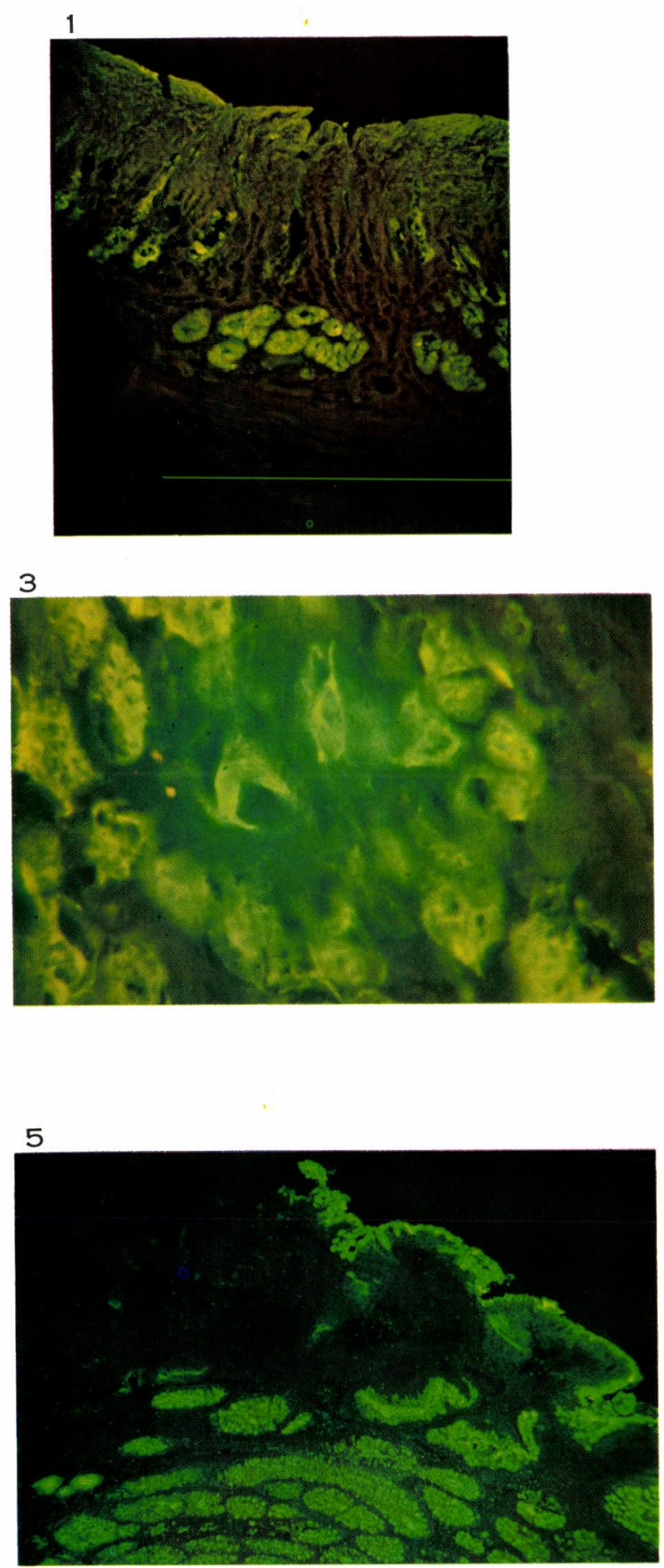
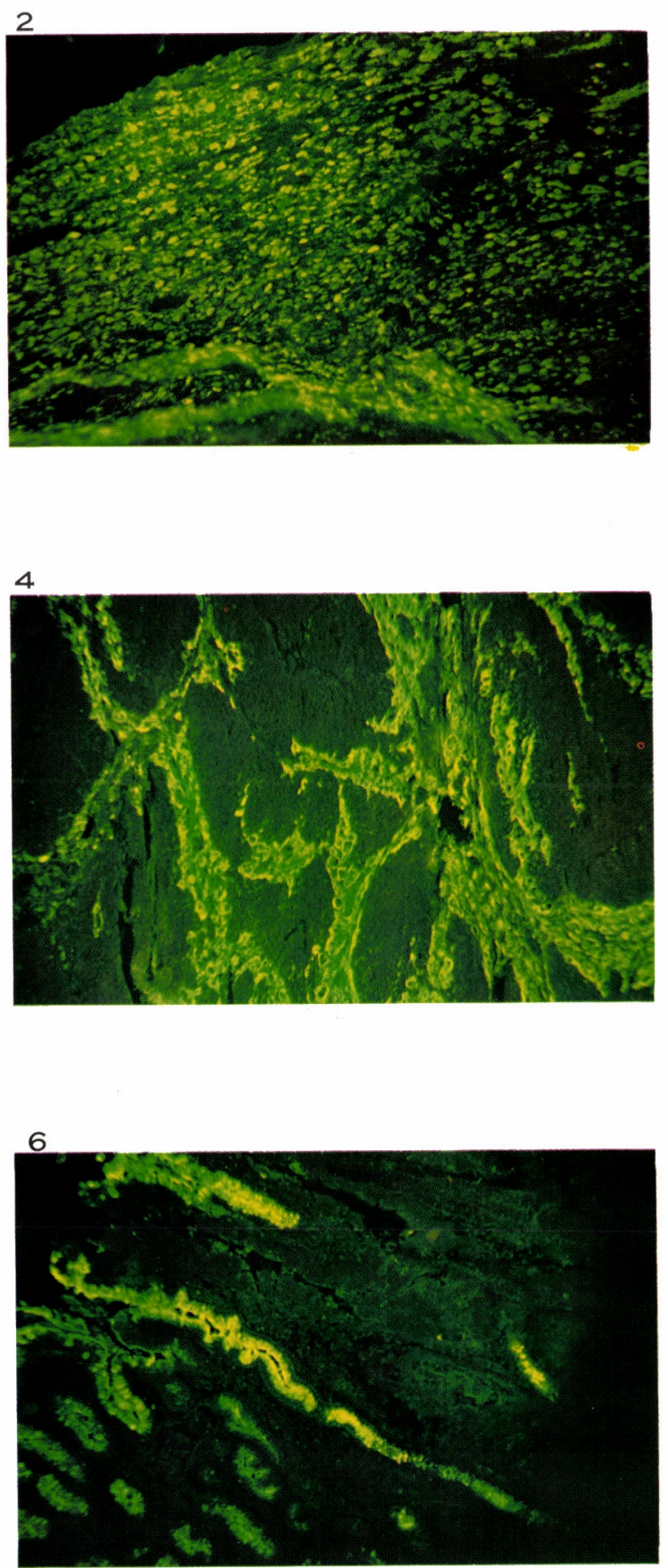

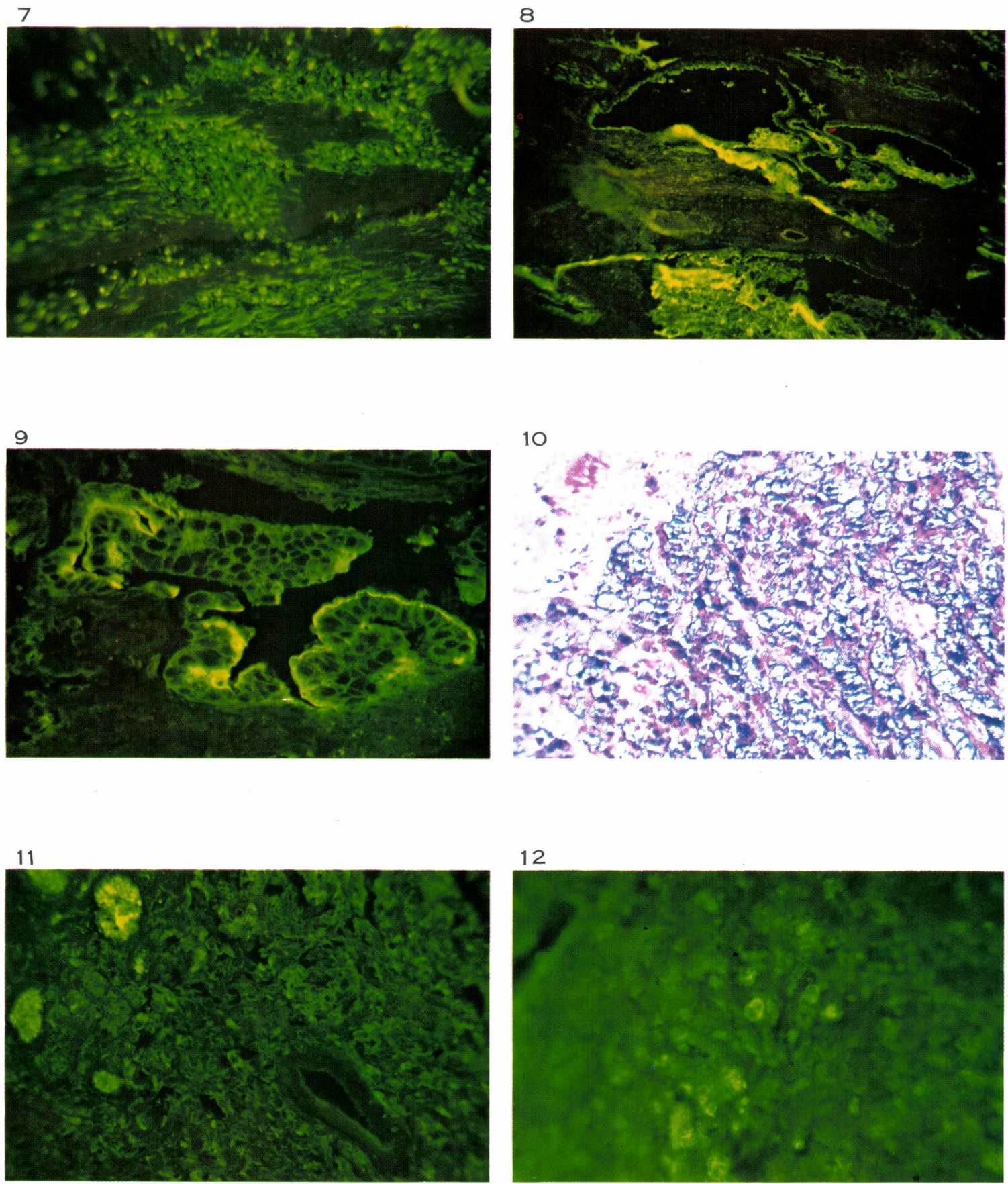